\title{
Variação anual de hormônios tireoideanos e características termorreguladoras de vacas leiteiras em ambiente quente ${ }^{1}$
}

\author{
Débora Andréa Evangelista Façanha Morais ${ }^{2}$, Alex Sandro Campos Maia ${ }^{2}$, Roberto Gomes da \\ Silva $^{3}$, Angela Maria de Vasconcelos ${ }^{4}$, Patrícia de Oliveira Lima ${ }^{5}$, Magda Maria Guilhermino 6 \\ 1 Projeto financiado pela FAPESP. \\ 2 Programa de Pós-Graduação em Zootecnia - UNESP - Jaboticabal. Docentes da Universidade Federal Rural do Semi-Árido-Departamento \\ de Ciências Animais. Caixa Postal 137, 59625-900, Mossoró-RN - Brasil; Tel.: (84) 3315.1760. \\ 3 Departamento de Zootecnia, Faculdade de Ciências Agrárias e Veterinárias, UNESP - Jaboticabal. \\ 4 Universidade Estadual Vale do Acaraú-Centro de Ciências Agrárias e Biológicas/Curso de Zootecnia. \\ 5 Programa de Doutorado Integrado, UFC - Fortaleza - CE. \\ ${ }_{6}^{6}$ Universidade Federal do Rio Grande do Norte - Departamento de Agropecuária.
}

RESUMO - Este trabalho foi conduzido com o objetivo de estudar o comportamento anual de características termorreguladoras de 200 vacas leiteiras. Durante dois anos consecutivos, foram registradas a frequiência respiratória (FR) e a temperatura retal (TR), bem como coletada uma amostra de sangue para dosagens de triiodotironina $\left(\mathrm{T}_{3}\right)$ e tiroxina $\left(\mathrm{T}_{4}\right)$. Foram também registradas a temperatura e a umidade do ar e calculados o índice de temperatura de globo e umidade (ITGU) e a carga térmica radiante (CTR), nos mesmos dias de coleta. Houve efeito significativo do ano para a maioria das variáveis estudadas, no entanto, os efeitos do mês de coleta e do rebanho foram significativos para todas. Todos os valores de TR estiveram dentro da amplitude de normalidade, indicando homeotermia. A FR foi alterada em todas as épocas do ano e rebanhos, confirmando a necessidade constante de termólise. No rebanho de maior TR e a FR, houve redução da secreção de $\mathrm{T}_{3}$ e $\mathrm{T}_{4}$. Nas épocas de maiores ITGU e CTR, houve aumento da TR, seguido de maiores FR e menores concentrações plasmáticas de $\mathrm{T}_{3}$ e $\mathrm{T}_{4}$.

Palavras-chave: bovinos leiteiros, estresse térmico, termorregulação

\section{Annual thyroid hormone variation and thermo regulators traits of milk cows in hot environment}

\begin{abstract}
This work was carried out with the objective to study the annual behavior of thermo regulators traits in dairy cows. Two hundred cows were used during two consecutive years and the respiratory rate (RR), rectal temperature (RT), as well as a blood sample was collected for triiodothyronin $\left(\mathrm{T}_{3}\right)$ and thyroxin $\left(\mathrm{T}_{4}\right)$ dosages, were recorded. Air temperature and humidity were also recorded and the black globe humidity index (BGHI) and radiant heat load (RHL) were calculated in the same days of data collection. There was no significative effect of the year for the majority of studied variables, however the effects of month of collection and herd were significative for all variables. All values of RT were inside of the amplitude of normality, indicating homoeothermic condition. The RR was altered in every seasons of the year and herds, showing a constant necessity of thermolisys. In herds with higher RT and $R R$, there was a reduction $T_{3}$ and $T_{4}$ liberation. In seasons of higher BGHI and RHL, there was increase in the RT, followed for higher RR and lower $\mathrm{T}_{3}$ and $\mathrm{T}_{4}$ plasmatic concentrations
\end{abstract}

Key Words: dairy cattle, thermal stress, thermoregulation

\section{Introdução}

Animais da raça Holandesa requerem temperaturas ambiente entre 5 e $18^{\circ} \mathrm{C}$ para a máxima expressão de seu potencial genético, porém, valores acima desta faixa são facilmente verificados na maioria das regiões do Brasil, durante boa parte do ano. Isto ocorre principalmente nas regiões de baixa latitude, caracterizadas por elevados níveis de radiação solar e altas temperaturas. Mesmo nestes casos, quando os mecanismos de termólise são acionados de maneira eficiente, os animais conseguem manter a homeotermia (Silva, 2000).

A temperatura corporal dos bovinos varia conforme a idade, raça e o estado fisiológico, entretanto, os valores 
considerados normais estão entre 38,8 e $39,5^{\circ} \mathrm{C}$ para animais adultos (Baccari Jr., 1990). Em contraste, quando os mecanismos de termólise não são eficientes, a soma da produção de calor metabólico com a fração de calor absorvida do meio passa a ser maior que a quantidade de calor eliminada pelas vias latente e sensível e, em consequiência, os animais passam a estocar calor, aumentando sua temperatura retal. Sob essas condições, a termólise evaporativa é o único meio efetivo de dissipação do excesso de calor corporal, sendo que a evaporação cutânea representa aproximadamente $85 \%$ da perda total de calor latente, enquanto o restante é perdido através da evaporação respiratória (Maia et al., 2005). Em adição, quando a temperatura corporal se eleva, uma das primeiras reações dos bovinos é aumentar a sudação e a frequiência respiratória, a fim de eliminar excesso de calor endógeno (Randal et al., 1997).

Outra reação importante verificada durante o estresse pelo calor é a alteração nas secreções de vários hormônios importantes para a lactação. Há diminuição nas secreções dos hormônios GH, tiroxina e triiodotironina, com conseqüente declínio na produção de leite, sobretudo nos estádios iniciais da lactação (Yousef, 1985). Essas alterações metabólicas possibilitam o equilíbrio de certas funções orgânicas relacionadas à termorregulação, porém, podem ocorrer prejuízos aos processos de síntese e secreção do leite. A explicação para o efeito do estresse sobre a lactação está primeiramente no fato de as reações por ele provocadas alterarem todo este complexo endócrino responsável pela lactogênese e galactopoiese (Ewy, 1987).

Assim, entre as mudanças endócrinas importantes por ocasião do estresse, pode-se destacar também a diminuição na atividade do eixo hipotálamo-hipófise-tireóide, com redução das concentrações de hormônios tireoideanos (Bianco \& Kimura, 1999). Várias pesquisas indicam que a glândula tireóide é sensível ao estresse térmico, pelo fato de seus hormônios estarem ligados à termogênese, uma vez que aumentam a taxa metabólica, além de apresentarem ação potenciadora sobre as catecolaminas. Portanto, $\mathrm{T}_{3}$ e $\mathrm{T}_{4}$ podem apresentar níveis reduzidos em animais expostos a altas temperaturas, associados à menor produção de calor metabólico (Johnson et al., 1988). Guerguiev (1999) e Pezzi et al. (2003) afirmam que a hipofunção da tireóide em bovinos durante a exposição crônica ao calor pode estar associada à necessidade de diminuição da taxa metabólica. No entanto, isto pode induzir mudanças em outras funções corporais, como diminuição no consumo de alimentos, no peso corporal e na secreção de leite, principalmente em situações de elevada produção.

Segundo Nascimento (1994), há necessidade também de se diferenciarem os efeitos de longa e curta duração do estresse pelo calor sobre os níveis circulantes de $\mathrm{T}_{3} \mathrm{eT}_{4} \mathrm{em}$ ruminantes, uma vez que a adaptação ao estresse crônico acarreta mudanças endócrinas que podem ser diferentes daquelas condicionadas pelo estresse momentâneo.

Na região Nordeste do Brasil, a maioria das propriedades leiteiras utiliza animais cruzados, com diversas proporções da raça Holandesa. Os rebanhos são geralmente obtidos por cruzamento absorvente, utilizando-se sêmen de touros provenientes de países temperados e cujas progênies sequer são avaliadas quanto às características físicas ou fisiológicas associadas à adaptabilidade. Portanto, objetivou-se com este estudo avaliar o comportamento anual de respostas fisiológicas ligadas à termorregulação, como temperatura corporal, frequiência respiratória e concentrações séricas de hormônios tireoideanos.

\section{Material e Métodos}

O estudo foi conduzido no município de Quixeramobim, Sertão Central do Ceará, situado a 211,72 m de altitude, nas coordenadas geográficas $5^{\circ} 30^{\prime}$ latitude sul e $39^{\circ} 18^{\prime}$ longitude oeste. O clima local, segundo a classificação de Köppen, é Bsh, semi-árido, com temperatura média anual de $27,1^{\circ} \mathrm{C}$, umidade relativa do ar em torno de $67 \%$ e precipitação pluviométrica média de $850 \mathrm{~mm}$ anuais. Na região observa-se a ocorrência de duas estações ao longo do ano: período chuvoso, de janeiro a maio, e período seco, de junho a dezembro. O nível médio de radiação solaré de 791,6 W/m² e o fotoperíodo médio, de 11,3 horas (FUNCEME, 1992).

Foram realizadas medidas repetidas no tempo em 200 vacas adultas, entre a $1^{\mathrm{a}}$ e $4^{\mathrm{a}}$ ordens de lactação, com proporções da raça Holandesa variando entre 3/4 e 31/32. Esses animais pertenciam a três propriedades comerciais que participavam de um programa de gerenciamento conduzido pela Prefeitura de Quixeramobim, no qual a assistência técnica padronizava os manejos alimentar, sanitário e reprodutivo, além de realizar rigorosa escrituração zootécnica.

O rebanho 1 era constituído de 150 animais, mestiços Holandês $\times$ SPRD, com proporção da raça Holandesa variando de $7 / 8$ a 31/32, que produziam média de $16 \mathrm{~kg}$ de leite/an/dia, dos quais foram utilizadas 40 vacas. No rebanho 2, formado por 250 animais mestiços Holandês $\times$ Zebu, com proporção da raça Holandesa variando de $7 / 8$ a $31 / 32$, foram utilizadas 50 vacas, que produziam média de $11 \mathrm{~kg}$ de leite/an/dia. O rebanho 3 contava com um plantel de 396 animais obtidos por cruzamento absorvente, usando como raça base a Guzerá, com grande número de animais 15/16 e 31/32 Holandês, sendo utilizadas 110 vacas neste estudo. A média de produção da propriedade era de $12 \mathrm{~kg} / \mathrm{an} /$ dia. Em todas as propriedades, adotava-se o 
sistema semi-intensivo de produção durante a época chuvosa, sendo a alimentação à base de capim-elefante (Pennisetum purpureum, Schum.) ou gramão (Cynodon dactylon L. Pers.), concentrado com 16 a $18 \%$ de PB e suplementação. Na época seca, os animais eram confinados em piquetes providos de estruturas de sombreamento artificial e árvores e recebiam suplementação com silagem de milho ou sorgo. Realizavam-se duas ordenhas diárias, com controle leiteiro quinzenal.

Os dados foram coletados durante dois anos consecutivos, em períodos com duração de aproximadamente 1 semana, nas épocas dos solstícios de inverno e de verão (dia 21 de junho e 21 de dezembro) e dos equinócios de primavera e de outono ( 21 de março e em 23 de setembro). Foi estabelecida a coleta apenas pela manhã, das 8 às $11 \mathrm{~h}$, devido ao ritmo circadiano dos hormônios da tireóide, eliminando os horários dos picos hormonais e, com isso, o risco de superestimar essas dosagens.

Após a ordenha da manhã, os animais utilizados no trabalho foram conduzidos aos piquetes onde normalmente vivem na fazenda. Somente em torno de 30 minutos após sua chegada no piquete, foi registrada a freqüência respiratória, pela contagem dos movimentos dos flancos durante 1 minuto, antes de se realizar qualquer outra movimentação que pudesse alterar essa variável nos animais. Em seguida, os animais foram levados ao tronco de contenção, onde se registrou a temperatura retal, por meio de um termômetro clínico digital de uso veterinário, introduzido no reto durante dois minutos. Na seqüência, coletou-se uma amostra de $10 \mathrm{~mL}$ de sangue de cada animal, através de punção na veia jugular ou na mamária, utilizando-se um sistema de coleta a vácuo, com anticoagulante (heparina sódica). Essas amostras foram acondicionadas em caixas térmicas e, no máximo 1 hora após a coleta, foram centrifugadas, sendo o plasma obtido congelado a $-20^{\circ} \mathrm{C}$, em tubos do tipo "eppendorf". As dosagens de triiodotironina (T3) e tiroxina (T4) foram realizadas no Laboratório de Bioclimatologia da UNESPFCAV-Jaboticabal, utilizando-se kits comerciais de imunofluorescência.

Nos dias de coleta dos dados, em cada fazenda, foram registradas, às $9 \mathrm{~h}$, as temperaturas de bulbo seco e de bulbo úmido, por meio de um psicrômetro portátil. A partir destes dados, foi estimada a pressão parcial de vapor, segundo Varejão-Silva (2001). Também foram registradas as velocidades do vento e as temperaturas de globo negro instalado no local onde se encontravam os animais. Com estas medidas foi calculado o índice de temperatura de globo e umidade (ITGU), desenvolvido por Buffington et al. (1981), bem como estimada a carga térmica radiante (CTR) em cada fazenda, nos dias de coleta, de acordo com Silva (2000).
A análise estatística foi realizada pelo método dos quadrados mínimos, conforme Harvey (1964), utilizando-se o programa SAS, versão 6.12 (SAS, 1998), tendo como base os seguintes modelos:

Modelo 1, utilizado para hormônios tireoideanos:

$$
\begin{gathered}
\mathrm{Y}_{\mathrm{ijklm}}=\alpha+\mathrm{R}_{\mathrm{i}}+\mathrm{V}_{\mathrm{ji}}+\mathrm{A}_{\mathrm{K}}+\mathrm{M}_{1}+\mathrm{I}_{\mathrm{ik}}+\mathrm{I}_{\mathrm{il}}+\mathrm{I} 3_{\mathrm{kl}}+ \\
\mathrm{b}_{1}\left(\mathrm{ITGU}_{\mathrm{ijkl}}\right)+\mathrm{b}_{2}\left(\mathrm{CTR}_{\mathrm{ijkl}}\right)+\mathrm{b}_{3}\left(\mathrm{FR}_{\mathrm{ijkl}}\right)+\mathrm{b}_{4}\left(\mathrm{TR}_{\mathrm{ijkl}}\right)+\mathrm{e}_{\mathrm{ijklm}},
\end{gathered}
$$

em que: $\mathrm{Y}_{\mathrm{ijklm}}$ é a m-ésima média de níveis circulantes de $\mathrm{T}_{3}$ ou $\mathrm{T}_{4}$, observado na m-ésima repetição no l-ésimo mês de coleta, no k-ésimo ano de coleta, na j-ésima vaca, pertencente ao i-ésimo rebanho; $\alpha$, o intercepto; $\mathrm{R}_{\mathrm{i}}$, o efeito fixo do i-ésimo rebanho ( $\mathrm{i}=1,2,3) ; \mathrm{V}_{\mathrm{ji}}$, o efeito aleatório da $\mathrm{j}$-ésima vaca pertencente ao i-ésimo rebanho; $A_{k}$, o efeito fixo do k-ésimo ano de coleta $\left(\mathrm{k}=1\right.$ e 2); $\mathrm{M}_{1}$, o efeito fixo do l-ésimo mês de coleta $(1=1, \ldots, 4) ; \mathrm{Il}_{\mathrm{ik}}$, o efeito da interação 1-ésimo rebanho $\times$ k-ésimo ano de coleta; $\mathrm{I}_{\mathrm{il}}$, o efeito da interação i-ésimo rebanho $\times$ l-ésimo mês de coleta; $\mathrm{I} 3_{\mathrm{kl}}$, o efeito da interação k-ésimo ano $\times 1$-ésimo mês de coleta; $b 1$, b2, b3 e b4, os coeficientes de regressão linear sobre o índice de temperatura de globo e umidade, carga térmica radiante, freqüência respiratória e temperatura retal, respectivamente; e $\mathrm{e}_{\mathrm{ijklm}}$, o resíduo, incluindo o erro aleatório.

O modelo 2, utilizado para freqüência respiratória foi:

$$
\begin{gathered}
\mathrm{Y}_{\mathrm{ijklm}}=\alpha+\mathrm{R}_{\mathrm{i}}+\mathrm{V}_{\mathrm{ji}}+\mathrm{A}_{\mathrm{K}}+\mathrm{M}_{1}+\mathrm{I}_{\mathrm{ik}}+\mathrm{I} 2_{\mathrm{il}}+\mathrm{I} 3_{\mathrm{kl}}+ \\
\mathrm{b}_{1}\left(\mathrm{ITGU}_{\mathrm{ijkl}}\right)+\mathrm{b}_{2}\left(\mathrm{CTR}_{\mathrm{ijkl}}\right)+\mathrm{b}_{3}\left(\mathrm{TR}_{\mathrm{ijkl}}\right)+\mathrm{e}_{\mathrm{ijklm}}
\end{gathered}
$$

Para a temperatura retal utilizou-se o modelo 3:

$$
\begin{gathered}
\mathrm{Y}_{\mathrm{ijklm}}=\alpha+\mathrm{R}_{\mathrm{i}}+\mathrm{V}_{\mathrm{ji}}+\mathrm{A}_{\mathrm{K}}+\mathrm{M}_{1}+\mathrm{I}_{\mathrm{ik}}+\mathrm{I}_{\mathrm{il}}+\mathrm{I}_{\mathrm{kl}}+ \\
\mathrm{b}_{1}\left(\mathrm{ITGU}_{\mathrm{ijkl}}\right)+\mathrm{b}_{2}\left(\mathrm{CTR}_{\mathrm{ijkl}}\right)+\mathrm{b}_{3}\left(\mathrm{FR}_{\mathrm{ijkl}}\right)+\mathrm{e}_{\mathrm{ijklm}}
\end{gathered}
$$

Os efeitos presentes nos modelos 2 e 3 são os mesmos descritos no modelo 1 .

\section{Resultados e Discussão}

Avaliando-se os dados constantes na Tabela 1, observa-se pequena amplitude anual para a temperatura do ar, com níveis máximos registrados nos meses de setembro, auge da estação seca, em ambos os anos. As temperaturas mínimas foram registradas no período marçojunho, provavelmente por ser a época de maiores nebulosidades e precipitação pluviométrica. A amplitude térmica anual foi de aproximadamente $5^{\circ} \mathrm{C}$, bastante inferior à verificada em regiões temperadas. Portanto, percebe-se que havia exposição crônica dos animais às altas temperaturas. 
Tabela 1 - Variáveis meteorológicas e índices de conforto térmico, registrados nas propriedades, nas diferentes épocas de coleta

\begin{tabular}{|c|c|c|c|c|c|c|c|}
\hline Evento astronômico & Mês de coleta & $\mathrm{T} \operatorname{Ar}\left({ }^{\circ} \mathrm{C}\right)$ & $\mathrm{VV}(\mathrm{m} / \mathrm{s})$ & $\operatorname{PP}\{\mathrm{ta}\}(\mathrm{Kpa})$ & $\mathrm{PPt}(\mathrm{mm})^{1}$ & ITGU & $\operatorname{CTR}\left(\mathrm{W} / \mathrm{m}^{2}\right)$ \\
\hline Solstício de verão & Dezembro/ano 1 & 30,8 & 2,39 & 2,61 & 14,6 & 90,53 & 768,77 \\
\hline Equinócio de outono & Março/Ano 1 & 25,1 & 2,84 & 2,69 & 151,2 & 92,18 & 713,69 \\
\hline Solstício de inverno & Junho/Ano 1 & 30,5 & 2,09 & 2,46 & 8,8 & 91,31 & 681,79 \\
\hline Equin. de primavera & Setembro/Ano 1 & 32,7 & 3,01 & 2,31 & 0,0 & 91,29 & 702,07 \\
\hline Solstício de verão & Dezembro/Ano 2 & 28,1 & 6,58 & 2,56 & 25,4 & 90,88 & 801,47 \\
\hline Equinócio de outono & Março/Ano 2 & 27,2 & 2,53 & 2,92 & 124,2 & 91,88 & 773,31 \\
\hline Solstício de inverno & Junho/Ano 2 & 26,2 & 2,23 & 2,59 & 80,0 & 87,46 & 666,99 \\
\hline Equin. de primavera & Setembro/Ano 2 & 31,8 & 3,23 & 2,43 & 73,1 & 92,02 & 699,78 \\
\hline
\end{tabular}

1 PPt: precipitação pluviométrica: valores mensais acumulados; T Ar: temperatura do ar; VV: velocidade do vento; PP(ta): pressão parcial de vapor à temperatura do ar; ITGU: índice de temperatura de globo e umidade; CTR: carga térmica radiante.

A velocidade do vento variou bastante ao longo do ano, com as maiores médias observadas em setembro e dezembro, amenizando a sensação de calor imposta pelas maiores temperaturas do ar nesta época. A umidade do ar e a precipitação pluviométrica exibiram comportamentos anuais paralelos, sendo registrados menores valores de umidade em setembro e dezembro, época de escassez de chuvas. Os maiores valores de março associados a temperaturas ambientes também elevadas, por sua vez, podem dificultar a dissipação de calor e tornar os animais um pouco mais estressados nesta época.

O índice de temperatura de globo e umidade (ITGU) praticamente não variou e apresentou valores altos, caracterizando ambiente estressante em todas as épocas do ano. Porém, não se sabe se esses valores de ITGU podem ser considerados tão críticos para o gado mestiço. É possível que o impacto desse índice seja maior sobre o gado Holandês puro, que foi o tipo racial utilizado para o seu desenvolvimento (Buffington et al., 1981).

A carga térmica radiante (CTR) está intimamente relacionada às trocas térmicas por radiação entre animal e ambiente, portanto, em regiões tropicais, são desejáveis os menores valores possíveis de CTR (Silva, 2000). Todavia, neste trabalho, a CTR foi constantemente alta e positiva ao longo do ano. Estes resultados alertam para a necessidade do manejo ambiental, visando à proteção contra a radiação e à seleção de animais que possam suportar melhor essas particularidades climáticas e apresentar menores perdas no desempenho.

A análise de variância mostrou que o efeito de rebanho foi significativo para todas as variáveis. O mês de coleta não influenciou as concentrações de $T_{3}$, porém, seu efeito foi observado sobre as concentrações de $T_{4}$, a frequiência respiratória (FR) e a TR.

A regressão sobre a carga térmica radiante (CTR) não influenciou as variáveis estudadas. O ITGU e a TR apresentaram efeito linear apenas sobre a FR. O coeficiente de regressão do ITGU e da TR sobre a FR foi, respectivamente, $\mathrm{b}=1,384 \mathrm{e} b=6,08$, indicando que, para cada $1^{\circ} \mathrm{C}$ de elevação da TR, ocorreu aumento de aproximadamente $6 \mathrm{mov} / \mathrm{min}$ na FR, porém, para cada unidade de diminuição no valor do ITGU, estimou-se que a FR poderia diminuir cerca de $1,4 \mathrm{mov} / \mathrm{min}$. Verificou-se também que, a cada movimento respiratório a mais, a TR aumentou $0,022^{\circ} \mathrm{C}$, provavelmente em decorrência da energia gerada com o maior esforço muscular envolvido na elevação da FR.

Foi detectada relação linear e negativa entre FR e os hormônios da tireóide, confirmando que, quando a termólise respiratória foi acionada em maior grau, tanto o $\mathrm{T}_{3}$ $(\mathrm{b}=-0,00972)$ quanto o $\mathrm{T}_{4}(\mathrm{~b}=-0,0379)$ diminuíram. Este fato pode ser interessante para animais criados em ambiente quente, pois o aumento da termólise, associado à diminuição da termogênese, pode contribuir para a manutenção da temperatura corporal fisiológica.

Nota-se que a média geral de triiodotironina $\left(\mathrm{T}_{3}\right)$, de $1,05 \mathrm{ng} / \mathrm{mL}$, encontra-se dentro dos valores de referência de $\mathrm{T}_{3}$ para bovinos, indicando que tanto as condições ambientais quanto as reações fisiológicas dos animais não alteraram os níveis circulantes desse hormônio (Tabela 2).

No entanto, em situações climáticas mais amenas, o $\mathrm{T}_{3}$ tende a apresentar-se em maiores níveis; Nascimento (2002) obteve média de $1,53 \mathrm{ng} / \mathrm{mL}$, em temperaturas variando de $20^{\circ} \mathrm{C} \mathrm{a} 29^{\circ} \mathrm{C}$. Isto confirma que, mesmo o $\mathrm{T}_{3}$ sendo responsável pela termogênese obrigatória, outros fatores além da temperatura ambiente podem regular a sua síntese.

Os animais do rebanho 1, com maior proporção da raça Holandesa, apresentaram as menores médias de $\mathrm{T}_{3}$. Como os hormônios tireoideanos estimulam a termogênese em vários tecidos, é possível que, em animais menos adaptados, a redução da secreção de $\mathrm{T}_{3}$ ajude a diminuir a produção de calor endógeno, na tentativa de se ajustar a ambientes quentes.

A média geral de tiroxina $\left(\mathrm{T}_{4}\right)$ obtida foi de $6,02 \mu \mathrm{g} / \mathrm{dL}$, valor que se encontra dentro da faixa de normalidade para bovinos leiteiros (Sutherland \& Irvine, 1973). No Brasil, a literatura cita níveis médios de $\mathrm{T}_{4}$, que variam de $7,4 \mu \mathrm{g} / \mathrm{dL}$, 
em vacas criadas no Triângulo Mineiro, a 3,39 $\mu \mathrm{g} / \mathrm{dL}$, em ambiente climatizado, com temperatura entre 18 e $28^{\circ} \mathrm{C}$. Porém, os níveis de $\mathrm{T}_{4}$ variam conforme a idade, o estado fisiológico, a ordem de lactação e fatores ambientais como diferenças climáticas que ocorrem ao longo do ano (Nascimento, 2002).

As menores médias foram constatadas nos rebanhos 1 e 3, que foram semelhantes entre si. É importante ressaltar que estes rebanhos eram compostos, respectivamente, por animais de maior e menor proporção da raça Holandesa, portanto, com diferentes graus de adaptabilidade.

Por outro lado, é possível que, no rebanho 1, cujo nível produtivo era maior e o metabolismo dos animais era mais intenso, se observe menor secreção de $\mathrm{T}_{4}$, na tentativa de reduzir a produção de calor metabólico, favorecendo a homeotermia. Já os animais do rebanho 3 foram obtidos por cruzamento absorvente com vacas da raça Guzerá, portanto, são animais adaptados, nos quais esses ajustes já podem ter sido realizados no processo de aclimatação, levando a menores níveis basais de $\mathrm{T}_{4}$. No rebanho 2 os valores foram maiores e variaram mais ao longo do ano, refletindo a tentativa de ajuste dos animais às variações estacionais.

Todas as médias de freqüência respiratória (FR) durante o estudo foram mais altas que as consideradas normais para vacas adultas, que é em torno de 24 movimentos/minuto, em conforto térmico $\left(18^{\circ} \mathrm{C}\right)$, segundo Randall et al. (1997). Isto sugere a necessidade de utilização da termólise evaporativa, visando manter a homeotermia em todas as épocas do ano nos três rebanhos.

As médias de FR do rebanho 1 foram maiores que as dos rebanhos 2 e 3, demonstrando que neste primeiro rebanho os animais tiveram maior necessidade de dissipar calor. É possível que o conjunto de atributos físicos e fisiológicos desses animais, como características de pelame e secreção de hormônios calorigênicos, tenha contribuído para esse perfil adaptativo. As maiores médias de temperatura retal (TR) foram verificadas nos rebanhos $2 \mathrm{e} 1$, respectivamente. No rebanho 3 a maior secreção de $\mathrm{T}_{3}$ pode elevar a temperatura corporal, porém, um aspecto que pode estar associado à menor TR é o fato de que os animais tiveram mais acesso a estruturas de sombra na propriedade, reduzindo a absorção de radiação.

Em relação ao ano de coleta, percebe-se que no ano 2 as concentrações de $T_{3}$ foram menores, enquanto as de $T_{4}$ foram superiores, indicando menor mobilização de $T_{4}$ para a síntese de $T_{3}$. A FR foi superior no segundo ano, demonstrando que os animais tiveram maior necessidade de utilização da termólise respiratória para manter a tempe- ratura corporal. O estoque de calor foi constante entre os anos, confirmado pelas TRs semelhantes.

Não houve variação significativa de $\mathrm{T}_{3}$ entre os meses do ano, no entanto, as concentrações mais altas de $\mathrm{T}_{4}$ foram verificadas em setembro e em junho, sugerindo que houve maior atividade do eixo hipotálamo-hipófise-tireóide nesta época. Entretanto, esta maior atividade sintética da tireóide provavelmente não foi acompanhada por mobilização de $\mathrm{T}_{4}$, uma vez que concentrações de $\mathrm{T}_{3}$ mantiveram-se estáveis entre os meses. A menor atividade tireoideana foi verificada em março e dezembro, quando, na maioria dos casos, ocorreram maiores CTR e ITGU (Tabela 1), ou seja, em épocas de maior desconforto térmico as concentrações de $\mathrm{T}_{4}$ foram diminuídas. De fato, era esperada esta sazonalidade nos níveis circulantes de hormônios da tireóide, pois os mesmos estão associados às mudanças metabólicas que permitem a aclimatização dos animais a ambientes quentes. Este resultado confirma outros estudos que relatam redução nas concentrações dos hormônios da tireóide em épocas mais quentes. Johnson et al. (1988) verificaram que o $\mathrm{T}_{4}$ diminuía de 7,97 para $5,35 \mu \mathrm{g} / \mathrm{dL}$, quando a temperatura ambiente se elevou de 18 para $38^{\circ} \mathrm{C}$.

As médias de TR demonstram que esta variável esteve sempre dentro da amplitude de normalidade, por volta das 9h, evidenciando que os mecanismos termorreguladores utilizados foram suficientes para compensar o estresse ambiental e que os animais conseguiram manter a homeotermia. As maiores médias ocorreram nos meses de março e dezembro. Nesta época, os altos valores de CTR indicam maior incidência de radiação, que pode ser absorvida pelos animais, resultando em aumento da temperatura corporal. Em paralelo, o ITGU elevado demonstra que os altos níveis de radiação foram combinados com alta umidade, dificultando a dissipação do excesso de calor corporal.

As médias de FR aumentaram no mês de março, época chuvosa, e depois tenderam a diminuir com a aproximação da época seca. É possível que as altas temperaturas associadas a elevadas umidades dificultem a termólise latente. Maia et al. (2005) verificaram que, quando a temperatura do ar encontrava-se entre 10 e $30^{\circ} \mathrm{C}$, as perdas latentes por evaporação cutânea foram mais importantes que as respiratórias e aumentaram de 30 para $350 \mathrm{~W} . \mathrm{m}^{-2}$.

Pires (1997) verificou que o aumento da temperatura e da umidade do ar resultou em elevação concomitante da TR (de 38,7 para $39,5^{\circ} \mathrm{C}$ ) e da FR (de 41 para $60 \mathrm{mov} / \mathrm{min}$ ) entre os meses de inverno e verão, respectivamente. Portanto, proteger os animais dos extremos climáticos nestas épocas pode diminuir a absorção de calor, o estresse térmico e levar a melhor desempenho produtivo. 
Tabela 2 - Concentrações plasmáticas de triiodotironina total $\left(T_{3}\right)$, tiroxina total $\left(T_{4}\right)$, frequência respiratória (FR) e temperatura retal (TR) de vacas leiteiras em Quixeramobim - CE

\begin{tabular}{lccccc}
\hline Efeito & $n$ & $\mathrm{~T}_{3}(\mathrm{ng} / \mathrm{mL})$ & $\mathrm{T}_{4}(\mu \mathrm{g} / \mathrm{mL})$ & FR $(\mathrm{mpm})$ & \\
\hline Rebanho & & & & \\
\hline 1 & 312 & $0,849 \mathrm{~b} \pm 0,020$ & $5,829 \mathrm{~b} \pm 0,115$ & $47 \mathrm{a} \pm 0,417$ & $39,27 \mathrm{ab} \pm 1,026$ \\
2 & 292 & $1,001 \mathrm{a} \pm 0,029$ & $8,018 \mathrm{a} \pm 0,163$ & $44 \mathrm{~b} \pm 0,500$ & $39,31 \mathrm{a} \pm 1,030$ \\
3 & 849 & $1,012 \mathrm{a} \pm 0,012$ & $5,654 \mathrm{~b} \pm 0,068$ & $45 \mathrm{~b} \pm 0,299$ & $39,20 \mathrm{~b} \pm 0,018$ \\
\hline Ano de coleta & & & & \\
\hline 1 & 789 & $1,093 \mathrm{a} \pm 0,016$ & $5,250 \mathrm{~b} \pm 0,087$ & $41 \mathrm{~b} \pm 1,093$ & $39,41 \mathrm{a} \pm 0,067$ \\
2 & 664 & $0,815 \mathrm{~b} \pm 0,021$ & $7,751 \mathrm{a} \pm 0,114$ & $49 \mathrm{a} \pm 1,411$ & $39,12 \mathrm{a} \pm 0,087$ \\
\hline Mês de coleta & & & & & \\
\hline Março & 396 & $0,976 \mathrm{a} \pm 0,024$ & $5,862 \mathrm{c} \pm 0,131$ & $49 \mathrm{a} \pm 0,900$ & $39,49 \mathrm{a} \pm 0,055$ \\
Junho & 329 & $0,888 \mathrm{a} \pm 0,029$ & $6,862 \mathrm{~b} \pm 0,161$ & $46 \mathrm{~b} \pm 0,879$ & $39,11 \mathrm{bc} \pm 0,054$ \\
Setembro & 328 & $0,975 \mathrm{a} \pm 0,034$ & $7,482 \mathrm{a} \pm 0,187$ & $44 \mathrm{~b} \pm 0,931$ & $39,02 \mathrm{c}$ \\
Dezembro & 400 & $0,976 \mathrm{a} \pm 0,019$ & $5,797 \mathrm{c} \pm 0,104$ & $42 \mathrm{~b} \pm 1,767$ & $39,44 \mathrm{ab} \pm 0,108$ \\
\hline Média geral & & 1,05 & 6,02 & 44 & 39,30 \\
\hline
\end{tabular}

Médias seguidas pelas mesmas letras não diferem entre si pelo teste Tukey a $5 \%$ de significância.

Verifica-se que não houve comportamento cíclico ao longo do ano para as variáveis estudadas, talvez porque os três rebanhos passavam por mudanças no manejo e no material genético e, embora as coletas tenham sido feitas nos mesmos animais nos dois anos, estes animais estavam em fase de ajuste fisiológico às novas condições de manejo (Tabela 3). Porém, percebe-se claramente que os períodos de maiores concentrações de $\mathrm{T}_{3}$ ocorreram nas ocasiões em que o $\mathrm{T}_{4}$ foi mobilizado, diminuindo suas concentrações plasmáticas. No segundo ano, as concentrações plasmáticas de T4 foram sempre superiores, demonstrando maior atividade sintética da tireóide nos três rebanhos. Isto pode refletir em aumento das taxas metabólicas, levando a maiores produções de leite. Para isto, é necessário ressaltar a importância de se selecionarem entre os animais mais produtivos aqueles com características físicas que favoreçam melhor seu equilíbrio térmico, além de promover a proteção contra os extremos climáticos e melhorar o conforto térmico ambiental.

A TR foi semelhante entre os anos, nos três rebanhos, exceto no ano 2, quando foram constatadas menores médias no rebanho 3, fato que pode ser explicado pela maior FR na mesma época, que certamente contribuiu para redução do estoque de calor corporal.

Considerando a interação rebanho $\times$ mês de coleta, verificam-se menores concentrações de T3 em março e dezembro no rebanho 1. Uma provável explicação é que este rebanho era composto por animais importados de outras regiões do Brasil ou animais com elevada proporção da raça Holandesa, obtidos por cruzamento absorvente, utilizando-se sêmen de touros provenientes de regiões tropicais. Assim, é possível que os mesmos, sendo mais sensíveis às peculiaridades climáticas da região, tenham necessitado reduzir seu metabolismo nas épocas mais estressantes. Alguns autores também detectaram diferenças sazonais nas concentrações plasmáticas de $\mathrm{T}_{3}$ em vacas leiteiras. Nardone et al. (1997) demonstraram que, em vacas da raça Holandesa em lactação, as médias de $\mathrm{T}_{3}$ circulante diminuíram de $1,35 \mathrm{ng} / \mathrm{mL}$ no inverno para 1,06 ng/mL no verão. Nascimento (2002), trabalhando em ambiente tropical, observou média de $1,76 \mathrm{ng} / \mathrm{mL}$ no mês de julho, quando a temperatura do ar foi $26^{\circ} \mathrm{C}$, e menor média $(1,33 \mathrm{ng} / \mathrm{mL})$ no mês de maio, quando a temperatura se elevou para $27,5^{\circ} \mathrm{C}$.

As concentrações de $T_{4}$ não variaram entre os meses nos rebanhos $1 \mathrm{e} 3$, ambos com médias inferiores ao rebanho 2, que apresentou a maior média do estudo, no mês de setembro. Infere-se, a partir destes resultados, que nos rebanhos 1 e 3 as alterações fisiológicas podem ter ocorrido na hipófise, reduzindo o estímulo do TSH sobre a tireóide, acarretando menor síntese de $\mathrm{T}_{4}$. No rebanho 2, pode ter ocorrido em vários tecidos corporais menor mobilização de $T_{4}$ para conversão em $T_{3}$, visto que os níveis deste último hormônio foram semelhantes entre os rebanhos na maioria das ocorrências.

Avaliando-se o efeito da interação ano $\times$ mês de coleta, nota-se que o $\mathrm{T}_{4}$ no ano 1 permaneceu praticamente estável e, no ano 2 , apresentou o pico em setembro. $\mathrm{OT}_{3}$ não seguiu o mesmo padrão de comportamento nos dois anos, porém, no ano 2 verificou-se redução significativa $(\mathrm{P}<0,05)$ das concentrações de dezembro a junho, época chuvosa e, conseqüentemente, de maior umidade do ar (Figura 1).

Analisando o efeito da interação ano $\times$ mês de coleta sobre as características termorreguladoras (Figura 2), 
Tabela 3 - Concentrações plasmáticas de triiodotironina total $\left(T_{3}, \mathrm{ng} / \mathrm{mL}\right)$, tiroxina total $\left(T_{4} \mu \mathrm{g} / \mathrm{dL}\right)$, freqüência respiratória ( $\mathrm{FR}$, mov/min) e temperatura retal $(\mathrm{TR}, \stackrel{\circ}{-})$, conforme as interações ano de coleta $x$ rebanho e mês de coleta $\mathrm{x}$ rebanho

\begin{tabular}{|c|c|c|c|c|c|}
\hline Efeito & & Variável & Rebanho 1 & Rebanho 2 & Rebanho 3 \\
\hline \multirow[t]{8}{*}{ Ano de coleta } & 1 & T3 & $0,964 \mathrm{bA} \pm 0,029$ & $1,033 \mathrm{bA} \pm 0,027$ & $1,283 \mathrm{aA} \pm 0,019$ \\
\hline & & $\mathrm{T} 4$ & $4,748 \mathrm{bB} \pm 0,161$ & $6,043 \mathrm{aB} \pm 0,153$ & $4,959 \mathrm{bB} \pm 0,103$ \\
\hline & & FR & $44 \mathrm{aA} \pm 1,17$ & $41 \mathrm{bA} \pm 1,13$ & $38 \mathrm{cB} \pm 1,13$ \\
\hline & & TR & $39,40 \mathrm{aA} \pm 0,072$ & $39,42 \mathrm{aA} \pm 0,069$ & $30,40 \mathrm{aA} \pm 0,069$ \\
\hline & 2 & T3 & $0,735 \mathrm{bB} \pm 0,029$ & $0,969 \mathrm{aA} \pm 0,050$ & $0,741 \mathrm{bB} \pm 0,021$ \\
\hline & & $\mathrm{T} 4$ & $6,910 \mathrm{bA} \pm 0,161$ & $9,993 \mathrm{aA} \pm 0,276$ & $6,349 \mathrm{cA} \pm 0,114$ \\
\hline & & FR & $49 \mathrm{bA} \pm 1,50$ & $47 \mathrm{bA} \pm 1,53$ & $51 \mathrm{aA} \pm 1,50$ \\
\hline & & $\mathrm{TR}$ & $39,14 \mathrm{aA} \pm 0,092$ & $39,21 \mathrm{aA} \pm 0,094$ & $39,01 \mathrm{bA} \pm 0,089$ \\
\hline \multirow[t]{16}{*}{ Mês de coleta } & Março & T3 & $0,753 \mathrm{bA} \pm 0,041$ & $1,048 \mathrm{aA} \pm 0,039$ & $1,130 \mathrm{aB} \pm 0,027$ \\
\hline & & $\mathrm{T} 4$ & $5,69 \mathrm{bA} \pm 0,23$ & $7,02 \mathrm{aC} \pm 0,22$ & $4,86 \mathrm{cA} \pm 0,15$ \\
\hline & & FR & $50 \mathrm{aA} \pm 1,04$ & $49 \mathrm{aA} \pm 1,11$ & $48 \mathrm{aA} \pm 0,89$ \\
\hline & & $\mathrm{TR}$ & $39,42 \mathrm{aA} \pm 0,092$ & $39,67 \mathrm{aA} \pm 0,067$ & $39,35 \mathrm{bA} \pm 0,055$ \\
\hline & Junho & T3 & $0,811 \mathrm{aA} \pm 0,045$ & $0,966 \mathrm{aA} \pm 0,064$ & $0,889 \mathrm{aB} \pm 0,028$ \\
\hline & & $\mathrm{T} 4$ & $5,91 \mathrm{bA} \pm 0,25$ & $8,54 \mathrm{aB} \pm 0,35$ & $6,13 \mathrm{bA} \pm 0,16$ \\
\hline & & FR & $49 \mathrm{aA} \pm 1,09$ & $43 \mathrm{bB} \pm 1,24$ & $47 \mathrm{aA} \pm 0,90$ \\
\hline & & TR & $39,04 \mathrm{aB} \pm 0,067$ & $39,23 \mathrm{aB} \pm 0,075$ & $39,05 \mathrm{aA} \pm 0,055$ \\
\hline & Setembro & T3 & $0,931 \mathrm{aA} \pm 0,041$ & $1,176 \mathrm{aA} \pm 0,071$ & $0,819 \mathrm{bB} \pm 0,032$ \\
\hline & & $\mathrm{T} 4$ & $5,83 \mathrm{bA} \pm 0,23$ & $10,48 \mathrm{aA} \pm 0,39$ & $6,13 b A \pm 0,18$ \\
\hline & & FR & $45 \mathrm{aB} \pm 1,09$ & $44 \mathrm{aB} \pm 1,31$ & $44 \mathrm{aB} \pm 0,96$ \\
\hline & & $\mathrm{TR}$ & $39,08 \mathrm{aB} \pm 0,066$ & $38,98 \mathrm{aB} \pm 0,079$ & $39,0 \mathrm{aA} \pm 0,058$ \\
\hline & Dezembro & T3 & $0,903 \mathrm{bA} \pm 0,039$ & $0,813 \mathrm{bB} \pm 0,034$ & $1,213 \mathrm{aA} \pm 0,029$ \\
\hline & & $\mathrm{T} 4$ & $5,89 \mathrm{aA} \pm 0,22$ & $6,02 \mathrm{aD} \pm 0,19$ & $5,49 \mathrm{aA} \pm 0,16$ \\
\hline & & FR & $43 \mathrm{aB} \pm 1,86$ & $41 \mathrm{aB} \pm 1,85$ & $41 \mathrm{aB} \pm 1,80$ \\
\hline & & $\mathrm{TR}$ & $39,55 \mathrm{aA} \pm 0,114$ & $39,36 \mathrm{bAB} \pm 0,113$ & $39,39 \mathrm{abA} \pm 0,111$ \\
\hline
\end{tabular}

Médias seguidas pelas mesmas letras minúsculas na linha e maiúsculas na coluna não diferem entre si pelo teste Tukey a $5 \%$ de significância.

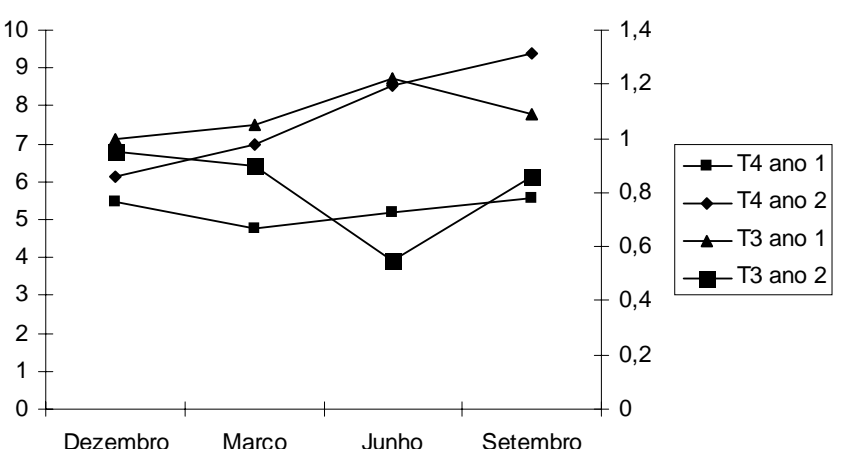

Figura 1 - Variações anuais das concentrações plasmáticas de triiodotironina $-\mathrm{T}_{3}(\mathrm{ng} / \mathrm{ml})$, de tiroxina $-\mathrm{T}_{4}-(\mu \mathrm{g} / \mathrm{dL})$ de vacas leiteiras em Quixeramobim - CE.

nota-se que as maiores médias de freqüência respiratória (FR) foram verificadas na época chuvosa (dezembromarço) com picos no mês de março, em ambos os anos. Esse comportamento pode ser atribuído ao maior aquecimento corporal, refletido no pico de TR $\left(39,63^{\circ} \mathrm{C}\right)$, que ocorreu também em março do ano 1. No ano 2, apesar de o pico de $\mathrm{TR}\left(39,41^{\circ} \mathrm{C}\right)$ não ter ocorrido exatamente em março,

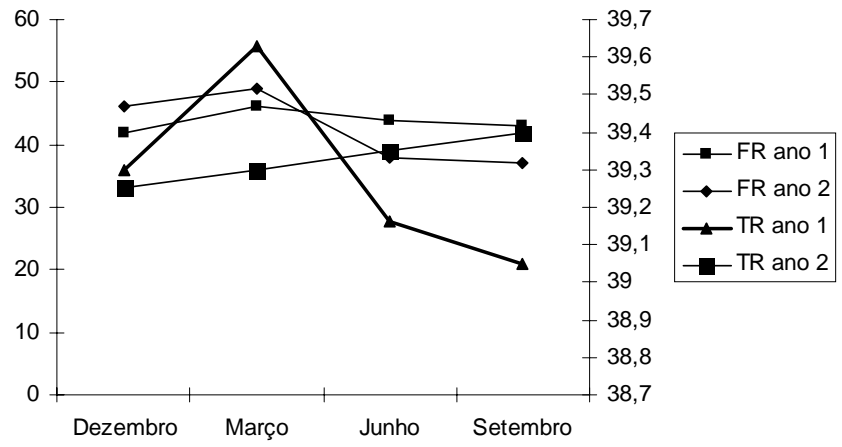

Figura 2 - Variações anuais das concentrações plasmáticas de triiodotironina $-T_{3}(\mathrm{ng} / \mathrm{mL})$, de tiroxina $-\mathrm{T}_{4}-(\mu \mathrm{g} / \mathrm{dL})$, freqüência respiratória (FR - $\mathrm{mov} / \mathrm{min}$ ) e temperatura retal $\left(T R-{ }^{\circ} \mathrm{C}\right)$ de vacas leiteiras em Quixeramobim - CE.

nota-se que houve tendência de elevação da TR a partir dessa época, com menores valores em dezembro.

Estas observações reforçam a necessidade de se identificarem as épocas mais críticas de cada ambiente em particular, quando a combinação dos elementos climáticos impõe maior estresse, para que se possa oferecer ou reforçar a proteção aos animais, fazendo com que estes possam 
melhorar seu desempenho e expressar todo seu potencial produtivo.

\section{Conclusões}

Os animais conseguiram manter a temperatura corporal estável ao longo do ano, porém na época chuvosa verificou-se maior estoque de calor endógeno. A termólise respiratória foi utilizada em todas as épocas do ano, sobretudo na época chuvosa, quando as temperaturas corporais foram maiores. As concentrações de triiodotironina foram constantes ao longo do ano, enquanto as de tiroxina aumentaram na época seca e diminuíram na época chuvosa.

\section{Agradecimento}

À Fundação de Amparo à Pesquisa do estado de São Paulo, pelo financiamento do projeto; aos produtores, que abriram as portas de suas propriedades à pesquisa; aos manejadores e técnicos que participaram do trabalho, especialmente à servidora Ângela Arduíno, do Laboratório de Bioclimatologia da UNESP - Jaboticabal.

\section{Literatura Citada}

BIANCO, A.C.; KIMURA, E.T. Fisiologia da glândula tireóide. In: AIRES, M.M. (Ed.) Fisiologia. Rio de Janeiro: Guanabara Koogan, 1999. p.812-828

BACCARI JR., F. A temperatura corporal dos bovinos. Revista do Gado Holandês, n.152, p.15-19, 1990.

BUFFINGTON, D.E.; COLAZZO-AROCHO, A.; CANTON, G.H. et al. Black globe-humidity index (BGHI) as comfort equation for dairy cows. Transactions of ASAE, v.24, n.3, p.711-714, 1981.

EWY, H.Z. The role of thyroid in lactation. Egypt Journal Veterinary Science, v.34, n.2, p.115-123, 1987.

FUNDAÇÃO CEARENSE DE METEOROLOGIA E RECURSOS HIDRICOS - FUNCEME. Relatório anual. Fortaleza: 1999. $49 \mathrm{p}$.

GUEORGUIEV, I.P. Thyroxine and triiodothyronine concentrations during lactation in dairy cows. Annales de Zootechnie, n.48, p.477-480, 1999.
HARVEY, W.R. Least squares analysis of data with unequal subclass numbers. Beltsville: ARS/USDA, 1960. 177p.

JOHNSON, H.D.; KATTI, P.S.; HAHN, L. et al. Short-term heat acclimatation effects on hormonal profile of lactating cows. Missouri: University of Missouri, 1988. 30p. (Research Bulletin).

MAIA, A.S.C.; SILVA, R.G.; LOUREIRO, C.M.B. Sensible and latent heat loss from the body surface of Holstein cows in a tropical environment. International Journal of Biometeorology, v.50, p.17-22, 2005.

NARDONE, A.; LACETERA, N.; BERNABUCCI, U. et al Composition of colostrum from dairy heifers exposed to high air temperatures during late pregnancy and the early postpartum period. Journal of Dairy Science, v.80, n.5, p.838-843, 1999.

NASCIMENTO, M.R.B.M. Níveis séricos de tiroxina $\left(\mathbf{T}_{4}\right)$ e $3,5,3$, triiodotironina $\left(T_{3}\right)$ relacionados ao efeito do mês, da ordem e do estágio de lactação em vacas das raças Holandesa e Guzerá. Jaboticabal: Universidade Estadual Paulista, 2002. 43p. Tese (Doutorado em Zootecnia) Universidade Estadual Paulista, 2002.

PEZZI, C.; ACCORSI, P.A.; GOVONI, N. et al. 5'-Deiodinase activity and circulating Thyronines in lactating cows. Journal of Dairy Science, v.86, n.1, p.152-158, 2003.

PIRES, M.F.A. Comportamento, parâmetros fisiológicos e reprodutivos de fêmeas da raça Holandesa confinadas em free-stall, durante o verão e o inverno. Belo Horizonte: Universidade Federal da Minas Gerais, 1997. 151p. Tese (Doutorado em Produção Animal) - Universidade Federal da Minas Gerais, 1997.

RANDALL, D.; BURGREEN, W.; FRENCH, K. Animal physiology: mechanisms and adaptations. 4.ed. New York: $\mathrm{H}$. W. Freeman and Company, 1997. 727p.

SILVA, R.G. Introdução à bioclimatologia animal. São Paulo: Nobel, 2000. 450p.

STATISTICAL ANALYSES SYSTEM - SAS. SAS/STAT - User's guide: version 6.12, 4.ed. Cary: 1998. 842p.

SUTHERLAND, R.L.; IRVINE, C.H.G. Total plasma thyroxine concentrations in horses, pigs, cattle and sheep: anion exchange resin chromatography and ceric-arsenite colorimetry. American Journal of Veterinary Research, v.34, n.10, p.6-10, 1973.

VAREJÃO-SILVA, M.A. Meteorologia e climatologia. Brasília: INMET, 2001. 532p.

WHITTOW, G.C. Comparative physiology of thermoregulation. New York: Academic Press, 1971. p.192-281.

YOUSEF, M.K. Stress physiology in livestock. Florida: Boca Raton, 1985. 171p.

YOUSEF, M.K.; JOHNSON, H.D. Some blood constituents of dairy cattle: influence of thyroxine and high environmental temperature. Journal of Animal Science, v.68, n.8, p.10741078, 1965. 